\title{
Variabilidade espacial da infiltração de água em solo sob pastagem em função da intensidade de pisoteio
}

\author{
Fernanda Ribeiro Marques Miguel(1), Sidney Rosa Vieira(1) e Célia Regina Grego ${ }^{(2)}$
} (1)Instituto Agronômico, Caixa Postal 18, CEP13001-970 Campinas, SP. E-mail: fernanda.mrosa@hotmail.com, sidney@iac.sp.gov.br
(2)Embrapa Monitoramento por Satélite, Avenida Soldado Passarinho, no 303, Fazenda Chapadão, CEP 13070-115 Campinas, SP.
E-mail: crgrego@cmpm.embrapa.br

\begin{abstract}
Resumo - O objetivo deste trabalho foi avaliar o efeito da intensidade de pisoteio do gado na variabilidade espacial da infiltração de água no solo. O experimento foi conduzido em um Argissolo Vermelho-Amarelo, com pastagem de Urochloa brizantha dividida em seis piquetes de 1 ha, cada um com 50 pontos de amostragem, em grade de 10x10 m. Em cada local de amostragem, foi medida a taxa de infiltração tridimensional de água em solo saturado, nas profundidades de 0,10 e $0,20 \mathrm{~m}$. As medições foram realizadas na primeira, décima primeira e décima quinta passagens do gado pelos piquetes. Os dados obtidos foram submetidos à análise geoestatística, para avaliação da variabilidade espacial das propriedades do solo. As 15 passagens do gado pelos piquetes resultaram em diminuição da taxa de infiltração de água no solo de $73,3 \%$ a $0,10 \mathrm{~m}$ e de $64,6 \%$ a $0,20 \mathrm{~m}$ de profundidade. $\mathrm{O}$ estudo da variabilidade espacial da taxa de infiltração de água no solo, por meio da geoestatística, possibilita a construção de mapas para a avaliação dos efeitos da intensificação do pisoteio do gado sobre as propriedades físicas do solo. A taxa de infiltração de água no solo apresenta estrutura de dependência espacial que aumenta em função da intensidade do pisoteio do gado.
\end{abstract}

Termos para indexação: dependência espacial, geoestatística, pastejo rotacionado, propriedades físicas, qualidade do solo.

\section{Spatial variability of water infiltration rate in soil under pasture as a function of cattle trampling intensity}

\begin{abstract}
The objective of this work was to evaluate the effect of cattle trampling intensity on the spatial variability of soil-water infiltration rate. The experiment was carried out on an Argissolo Vermelho-Amarelo (Ultisol) under a Urochloa brizantha pasture, divided into six one-hectare plots, each with 50 sampling points in a $10 \times 10 \mathrm{~m}$ grid. In each sampling site, the saturated three-dimensional infiltration rate at 0.10 and $0.20-\mathrm{m}$ depths was measured. Measurements were made in the first, eleventh and fifteenth cattle passages on the plots. Data were submitted to geostatistics for the study of the spatial variability of the saturated infiltration rate. The 15 cattle passages on the plots caused a decrease of $73.3 \%$ in the soil water infiltration rate, at $0.10-\mathrm{m}$ depth, and $64.4 \%$ at $0.20-\mathrm{m}$ depth. The study of spatial variability of soil-water infiltration rate with geostatistics permits the construction of maps for assessing the effects of cattle trampling intensification on soil physical properties. Water infiltration rate in soil has a spatial dependency structure which increases as a function of trampling intensity.
\end{abstract}

Index terms: spatial dependence, geoestatistics, rotational grazing, physical properties, soil quality.

\section{Introdução}

Em áreas de pastagens manejadas de forma ineficiente, normalmente sem rotação e com excesso de animais, é comum a presença de camadas compactadas pelo pisoteio dos animais (Souza et al., 2008). Em solo compactado, ocorre menor infiltração da água de chuvas e, assim, maior escoamento superficial, intensificado pelo aumento na declividade e presença de pouca matéria vegetal na superfície do solo. Além das consequências para a conservação dos solos, o adensamento e a baixa infiltração de água no solo tornam as plantas mais suscetíveis a deficits hídricos e com limitada capacidade de absorver nutrientes em camadas subsuperficiais (Rosolem et al., 1994).

Para Reichert et al. (2003), a qualidade física do solo está associada à boa infiltração, retenção e disponibilidade de água para as plantas. A taxa de infiltração de água é considerada, portanto, um bom indicativo desta qualidade (Bertol et al., 2000). 
Segundo Alves \& Cabeda (1999), esse é o atributo do solo que melhor reflete suas condições internas, como a distribuição de poros com tamanho favorável ao crescimento de raízes.

A dependência espacial da taxa de infiltração de água no solo é atribuída não apenas a processos de formação do solo, mas também a seus sistemas de manejo. Além disso, trata-se de um parâmetro com alta variabilidade espacial (Vieira et al., 1981) e, em pastagens, o hábito de pastejo do gado pode ser uma das causas para isso.

Bertol et al. (2000) observaram que, com o aumento da oferta de forragem, a taxa de infiltração de água no solo diminui, em razão de uma maior pressão média dos animais sobre o solo. Lanzanova et al. (2007) verificaram efeito semelhante na taxa de infiltração de água no solo, quando reduziram o intervalo entre pastejos de 28 para 14 dias.

A análise da variabilidade espacial da taxa de infiltração de água pode subsidiar o planejamento do manejo de áreas de pastagens, buscando, por exemplo, o grau de oferta de forragem no qual o aumento na intensidade de pastejo não prejudique a qualidade das propriedades do solo. Técnicas como a geoestatística podem permitir o conhecimento da estrutura espacial e temporal dessa variável, bem como estimar os valores de variáveis correlacionadas. A geoestatística também permite analisar adequadamente dados experimentais que, muitas vezes, são mal interpretados por se considerar a hipótese de aleatoriedade verdadeira, sem a ocorrência de dependência espacial.

O presente trabalho teve como objetivo avaliar o efeito da intensidade de pisoteio na variabilidade espacial da infiltração de água em solo sob pastagem, em piquetes plantados com braquiária brizanta (Urochloa brizantha), submetida a pastejo rotacionado.

\section{Material e Métodos}

O experimento foi conduzido no Polo Regional de Desenvolvimento de Tecnologias do Agronegócio do Centro Norte, em Pindorama, SP. O solo da área experimental é classificado como Argissolo Vermelho-Amarelo distrófico típico, textura entre arenosa e média (Santos et al., 2006). O clima da região é do tipo Cwa: tropical úmido com estação chuvosa no verão e seca no inverno, segundo Köppen.

$\mathrm{O}$ experimento foi realizado em solo sob pastagem de braquiária brizanta, em uma área de seis hectares, dividida em seis piquetes de um hectare cada. A área foi manejada com o sistema de pastejo rotacionado, com gado leiteiro, e taxa de lotação média de $6 \mathrm{UA} \mathrm{ha}^{-1}$, no período estudado. A raça predominante foi a Holandesa, com animais nas idades de dois a cinco anos. O período de ocupação dos piquetes foi de seis dias, e o descanso e a renovação do capim ocorreram por períodos de 30 dias.

Cada um dos piquetes foi demarcado com 50 pontos de amostragem, em grade de 10x10 m, no total de 300 pontos (seis piquetes). Em cada ponto, foi determinada a taxa de infiltração tridimensional de água no solo saturado, nas profundidades de 0,10 e 0,20 m. Segundo Prevedello \& Reichardt (1991), a infiltração tridimensional considera as componentes direcionais dos fluxos na vertical, horizontal e no declive. Para tanto, abriu-se um orifício no solo, com um trado holandês, até a profundidade desejada, e mediu-se a taxa de infiltração de água em cada ponto com o permeâmetro modelo IAC, com carga hidráulica constante de $5 \mathrm{~cm}$, de acordo com Vieira (1998). Foi calculada a infiltração saturada tridimensional, tendo-se usado a taxa de fluxo constante e a geometria do orifício, pela relação entre o volume de água infiltrada e a área molhada do orifício, de acordo com a expressão:

$\mathrm{I}=60\left(\frac{\mathrm{D}_{\mathrm{p}}^{2}}{\mathrm{D}_{\mathrm{o}}^{2}+4 \mathrm{D}_{\mathrm{o}} \mathrm{H}_{2}}\right) \mathrm{Q}$, em que: I é a infiltração $\left(\mathrm{mm} \mathrm{h}^{-1}\right)$; Q é a taxa de infiltração constante $\left(\mathrm{mm} \mathrm{min}^{-1}\right)$; $\mathrm{D}_{\mathrm{o}}$ é o diâmetro do orifício $(\mathrm{cm}) ; \mathrm{H}_{2}$ é a carga hidráulica usada $(\mathrm{cm})$; e $\mathrm{D}_{\mathrm{p}}$ é o diâmetro do reservatório do permeâmetro $(\mathrm{cm})$.

As medições foram efetuadas em três épocas: em agosto de 2004, após a primeira passagem do gado pelos piquetes; em setembro de 2005, após a décima primeira passagem; e em janeiro de 2006, após a décima quinta passagem. Os dados obtidos no campo foram submetidos à estatística descritiva, tendo-se determinado: média, desvio-padrão, coeficiente de variação, assimetria e curtose. $\mathrm{O}$ ajuste dos dados à distribuição foi avaliado pelo teste de Kolmogorov-Smirnov.

Para verificar a variabilidade espacial das variáveis ao longo do tempo, os resultados foram analisados por meio de métodos geoestatísticos de análise de semivariogramas (Vieira, 2000). A autocorrelação espacial entre locais vizinhos foi calculada por meio da semivariância $\gamma(\mathrm{h})$, estimada pela equação: $\gamma(h)=\frac{1}{2 N(h)} \sum_{I=1}^{N}\left[Z\left(x_{i}\right)-Z\left(x_{i}+h\right)\right]^{2}$, em que: $N(h)$ é o número de pares dos valores medidos $\mathrm{Z}\left(\mathrm{x}_{\mathrm{i}}\right)$ e $\mathrm{Z}\left(\mathrm{x}_{\mathrm{i}}+\mathrm{h}\right)$, 
separados por um vetor $h$, que é a distância determinada a partir das coordenadas de $\mathrm{Z}\left(\mathrm{x}_{\mathrm{i}}\right)$ e de $\mathrm{Z}\left(\mathrm{x}_{\mathrm{i}}+\mathrm{h}\right)$.

Os valores de $\gamma(\mathrm{h})$, portanto, são correspondentes às distâncias $h$, e o gráfico gerado com esses valores é denominado semivariograma. Modelos matemáticos - esférico, exponencial e gaussiano - foram ajustados aos semivariogramas para a visualização da natureza da variação espacial das variáveis. O ajuste de um modelo teórico ao semivariograma experimental é um dos aspectos mais importantes das aplicações da teoria das variáveis regionalizadas (Vieira et al., 1983) e, por isso, o modelo adequado foi escolhido pelo método de tentativa e erro, aliado ao exame dos resultados da validação cruzada, conforme Vieira (2000).

A partir do ajuste de um modelo matemático aos dados, foram definidos os seguintes parâmetros do semivariograma: o efeito pepita $\left(\mathrm{C}_{0}\right)$, que é o valor de $\gamma$ quando $h=0$; o alcance da dependência espacial (a), que é a distância em que $\gamma(\mathrm{h})$ permanece aproximadamente constante após aumentar com o incremento de $\mathrm{h}$; e o patamar $\left(\mathrm{C}_{0}+\mathrm{C}_{1}\right)$, que é o valor de $\gamma(\mathrm{h})$ a partir do alcance e que se aproxima da variância dos dados, se ela existir.

Foi calculado o grau de dependência espacial (GD), de acordo com o proposto por Zimback (2001), que o classifica em fraco, para GD $<25 \%$; moderado, para GD entre 25 e $75 \%$; e forte, para GD $>75 \%$, conforme a equação: $\mathrm{GD}=100\left(\mathrm{C}_{1} / \mathrm{C}_{0}+\mathrm{C}_{1}\right)$, em que $\mathrm{C}_{1}$ é variância estrutural, e $\mathrm{C}_{0}+\mathrm{C}_{1}$ é o patamar.

$\mathrm{O}$ resultado do trabalho foi expresso em forma de mapas de isolinhas, e a maneira de localizar uma isolinha entre dois pontos foi determinada pela interpolação dos dados, por meio de krigagem ordinária. O programa Surfer (Golden Software, 1999) foi utilizado para manipulação e visualização da distribuição espacial, por meio da construção de mapas de isolinhas das variáveis, de acordo com as coordenadas geográficas. A análise e os mapas foram feitos tratando-se a área de pastagem como um todo, sem a divisão em piquetes.

\section{Resultados e Discussão}

Durante o período avaliado, as médias da taxa de infiltração de água no solo decresceram aproximadamente 73,3 e $64,6 \%$ a 0,10 e $0,20 \mathrm{~m}$ de profundidade, respectivamente (Tabela 1). Observou-se redução gradativa da infiltração a cada passagem do gado avaliada, o que indica a ocorrência de compactação do solo, em razão do pisoteio do gado. A maior redução na taxa de infiltração de água foi observada a $0,10 \mathrm{~m}$ de profundidade. Segundo Bertol et al. (2000), o manejo de animais sobre as pastagens causa modificações nas propriedades físicas do solo em médio e longo prazos, e as pressões aplicadas pelo pisoteio dos animais ocasionam alterações na densidade e na porosidade do solo, principalmente à profundidade de 0-0,05 m.

Considerando-se a classificação proposta por Gomes (2000), os parâmetros estatísticos da permeabilidade do solo a 0,10 e $0,20 \mathrm{~m}$ indicaram alta variabilidade nos dados, com coeficientes de variação $(\mathrm{CV})$ muito altos $(>30 \%)$ (Tabela 1). Isso pode evidenciar as alterações provocadas pelo pisoteio mais intenso do gado em determinadas regiões, o que já era de se esperar, uma vez que estes animais têm hábito de formar trilhas de caminhamento. O coeficiente de variação é bastante útil na avaliação da dispersão dos dados em torno da média, mas não é necessariamente um bom indicador da variabilidade espacial dos atributos do solo, já que não mostra como estes se comportam espacialmente.

Os altos valores de assimetria e curtose mostram que a distribuição dos resultados não apresentou normalidade, o que também foi detectado pelo teste

Tabela 1. Parâmetros estatísticos descritivos, relativos à infiltração de água a 0,10 e $0,20 \mathrm{~m}$ de profundidade, em solo sob pastagem de braquiária brizanta, após a primeira (agosto de 2004), a décima primeira (setembro de 2005) e a décima quinta (janeiro de 2006) passagens do gado (taxa de lotação de $6 \mathrm{UA} \mathrm{ha}^{-1}$ ) pelos piquetes do sistema rotacionado de pastejo.

\begin{tabular}{|c|c|c|c|c|c|c|}
\hline Época $^{(1)}$ & Média & Desvio-padrão & CV (\%) & Assimetria & Curtose & $\mathrm{d}^{(2)}$ \\
\hline & \multicolumn{6}{|c|}{ Infiltração da água no solo $\left(\mathrm{mm} \mathrm{h}^{-1}\right)$ a $0,10 \mathrm{~m}$ de profundidade } \\
\hline Agosto/2004 & 215,40 & 139,50 & 64,74 & 1,09 & 1,16 & 0,14 \\
\hline Setembro/2005 & 81,81 & 59,89 & 73,21 & 1,41 & 2,56 & 0,16 \\
\hline \multirow[t]{2}{*}{ Janeiro/2006 } & 57,50 & 51,38 & 89,36 & 2,02 & 4,30 & 0.21 \\
\hline & \multicolumn{6}{|c|}{ Infiltração da água no solo $\left(\mathrm{mm} \mathrm{h}^{-1}\right)$ a $0,20 \mathrm{~m}^{2}$ de profundidade } \\
\hline Agosto/2004 & 187,20 & 136,50 & 72,90 & 1,52 & 2,80 & 0,16 \\
\hline Setembro/2005 & 128,10 & 100,70 & 78,59 & 1,86 & 5,04 & 0,17 \\
\hline Janeiro/2006 & 66,33 & 78,43 & 118,30 & 2,96 & 11,60 & 0,22 \\
\hline
\end{tabular}

(1)As épocas representam as diferentes intensidades de pisoteio. ${ }^{(2)}$ Significância estatística do teste de Kolmogorov-Smirnov. 
de Kolmogorov-Smirnov. Segundo Freeze (1975), é comum, em análise hidrológica de solos, admitir-se que a taxa de infiltração de água apresenta distribuição log-normal. A ausência de normalidade em dados de infiltração de água no solo também foi verificada por Cichota et al. (2003), Montenegro \& Montenegro (2006) e Calheiros et al. (2009). Todavia, a normalidade dos dados não é uma exigência da geoestatística, ainda que seja conveniente que a distribuição de frequências não apresente caudas muito alongadas - o coeficiente de assimetria deve ser próximo a zero - e que os semivariogramas apresentem patamares bem definidos, de forma a não comprometer as análises (Cressie, 1991), já que a estimativa por krigagem é baseada nos valores médios (Isaaks \& Srivastava, 1989).

O grau de dependência espacial (GD) foi classificado, de acordo com Zimback (2001), como moderado, para todas as medições da taxa de infiltração de água a $0,10 \mathrm{~m}$ e para a medição de setembro, a $0,20 \mathrm{~m}$ de profundidade (Tabela 2). No entanto, o GD à profundidade de $0,20 \mathrm{~m}$, em agosto, foi fraco e, em janeiro, forte. Isto indica que, com exceção dos dados de janeiro a $0,20 \mathrm{~m}$ de profundidade, a variabilidade devida ao acaso, em distâncias menores que a distância entre os pontos amostrais, apresentou contribuição significativa para a variância total da taxa de infiltração de água, na pastagem de braquiária brizanta. Adicionalmente, para as duas profundidades avaliadas, os GDs foram crescentes ao longo do período estudado, o que mostra maior dependência espacial na área, ou seja, maior homogeneidade entre os pontos amostrais. Essa crescente dependência espacial pode ser atribuída a um fator extrínseco, no caso o pastejo do gado, que influenciou na homogeneização do solo ao longo do tempo. Deve-se observar, ainda, que a dependência espacial observada, de moderada a forte, caracteriza a necessidade do uso de ferramenta que necessariamente a expresse - tal como a krigagem ordinária - a fim de se delimitarem possíveis zonas de manejo diferenciado.

Com relação ao alcance de GD, todas as variáveis apresentaram valores maiores que a grade amostral $(10 \times 10 \mathrm{~m})$ utilizada, o que evidencia a adequação do espaçamento de amostragem, na caracterização da dependência espacial da área, já que o alcance da dependência espacial representa a distância máxima a qual um atributo está correlacionado espacialmente, ou seja, o seu valor garante que todos os vizinhos situados dentro de um círculo, com raio igual ao alcance, sejam similares, e que possam ser usados para estimar valores em qualquer ponto entre eles (Vieira \& Lombardi Neto, 1995).

O uso dos semivariogramas para a análise geoestatística permitiu verificar a presença de dependência espacial nas propriedades analisadas, a partir dos parâmetros da Tabela 2 e do ajuste do modelo matemático que melhor ilustrasse o comportamento espacial da variável em função da distância. Todos os semivariogramas experimentais apresentaram patamares definidos e ajustaram-se ao modelo esférico (Figura 1). Segundo Grego \& Vieira (2005), o modelo matemático esférico é o que predomina nos trabalhos em ciência do solo.

Os parâmetros dos modelos de semivariogramas ajustados foram utilizados para estimar valores de infiltração em locais não amostrados, por meio da krigagem ordinária (Figura 2). De acordo com os mapas de krigagem, verifica-se a existência de valores maiores da taxa de infiltração de água no lado inferior esquerdo da área, tanto para $0,10 \mathrm{~m}$ como para $0,20 \mathrm{~m}$ de profundidade. Isto pode ter ocorrido em razão de a topografia do terreno apresentar declive nesse sentido, o que influenciaria no escoamento da água na direção

Tabela 2. Parâmetros dos semivariogramas relativos à infiltração de água a 0,10 e 0,20 m de profundidade, em solo sob pastagem de braquiária brizanta, após a primeira (agosto de 2004), a décima primeira (setembro de 2005) e a décima quinta (janeiro de 2006) passagens do gado (taxa de lotação de $6 \mathrm{UA} \mathrm{ha}^{-1}$ ) pelos piquetes do sistema rotacionado de pastejo.

\begin{tabular}{|c|c|c|c|c|c|}
\hline Época $^{(1)}$ & Efeito pepita & Variância estrutural & Alcance & $\mathrm{R}^{2}$ & Grau de dependência \\
\hline \multicolumn{6}{|c|}{ Infiltração da água no solo $\left(\mathrm{mm} \mathrm{h}^{-1}\right)$ a $0,10 \mathrm{~m}$ de profundidade } \\
\hline Agosto/2004 & 8.300 & 6.000 & 150 & 0,93 & 41,96 \\
\hline Setembro/2005 & 1.500 & 1.800 & 75 & 0,66 & 54,55 \\
\hline Janeiro/2006 & 1.200 & 1.950 & 160 & 0,77 & 61,90 \\
\hline \multicolumn{6}{|c|}{ Infiltração da água no solo $\left(\mathrm{mm} \mathrm{h}^{-1}\right)$ a $0,20 \mathrm{~m}$ de profundidade } \\
\hline Agosto/2004 & 6.600 & 1.850 & 30 & $-0,48$ & 21,89 \\
\hline Setembro/2005 & 6.500 & 2.300 & 30 & $-0,02$ & 26,14 \\
\hline Janeiro/2006 & 1.400 & 6.000 & 160 & 0,82 & 81,08 \\
\hline
\end{tabular}

${ }^{(1)}$ As épocas representam as diferentes intensidades de pisoteio. 
descendente do mapa. Adicionalmente, as alterações na taxa de infiltração de água com a intensidade de pisoteio do gado podem favorecer a ocorrência de escoamento superficial e alterar a drenagem natural característica do solo. Resultados semelhantes foram encontrados por Kurz et al. (2006), em estudos sobre o impacto do pisoteio do gado nas propriedades físicas e químicas do solo. Esses autores mostraram, também, que a presença de animais em pastejo leva ao aumento da concentração de nitrogênio, fósforo e potássio na água do escoamento superficial, com influência sobre a fertilidade do solo e sobre o potencial poluidor das enxurradas.

De acordo com Silva et al. (2003) e Sarmento et al. (2008), o efeito do pisoteio dos animais sobre o solo aumenta quando o pastejo é realizado em solos com umidade elevada e com baixa cobertura vegetal. Isto evidencia a importância do controle das taxas de lotação animal quanto à quantidade de pastagem produzida e à cobertura vegetal, para mitigar o efeito do pisoteio sobre a qualidade física dos solos. No presente trabalho, a época de menor taxa de infiltração de água no solo foi durante o período chuvoso de janeiro de 2006 (Figura 2). Esse resultado, somado ao possível controle inadequado
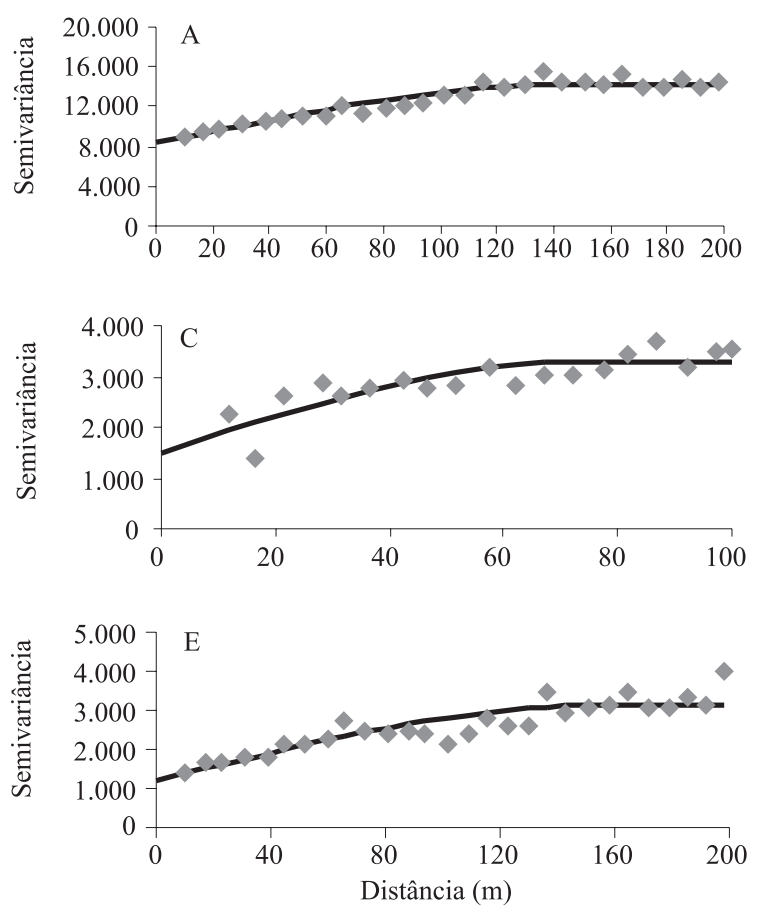

da taxa de lotação animal e da oferta de forragem, pode ter resultado em efeitos mais pronunciados do pisoteio sobre a infiltração de água no solo, especialmente nos piquetes localizados na região superior do mapa, os quais deveriam receber melhor atenção no seu manejo, em razão da menor infiltração de água.

Fidalski et al. (2008), ao estudar a qualidade física de um Latossolo Vermelho distrófico sob pastagem, verificaram que o pastejo não compromete a qualidade física do solo em sistema de lotação contínua, com controle da taxa de lotação animal, manutenção da massa de forragem e adubação com nitrogênio. Além disso, Bertol et al. (2000), ao estudar a relação das propriedades físicas do solo com os níveis de oferta de forragem, estabeleceram o nível crítico de $12 \%$ do peso vivo como limite máximo de oferta de forragem, para que a pressão de pastejo não alterasse significativamente as propriedades físicas do solo. Lanzanova et al. (2007), ao trabalhar com diferentes sistemas de pastejo integrados com agricultura, em um Argissolo Vermelho-Amarelo, observaram que a taxa de infiltração de água no solo não foi alterada após o cultivo de milho, em razão do elevado aporte e manutenção de resíduos culturais na superfície do solo.
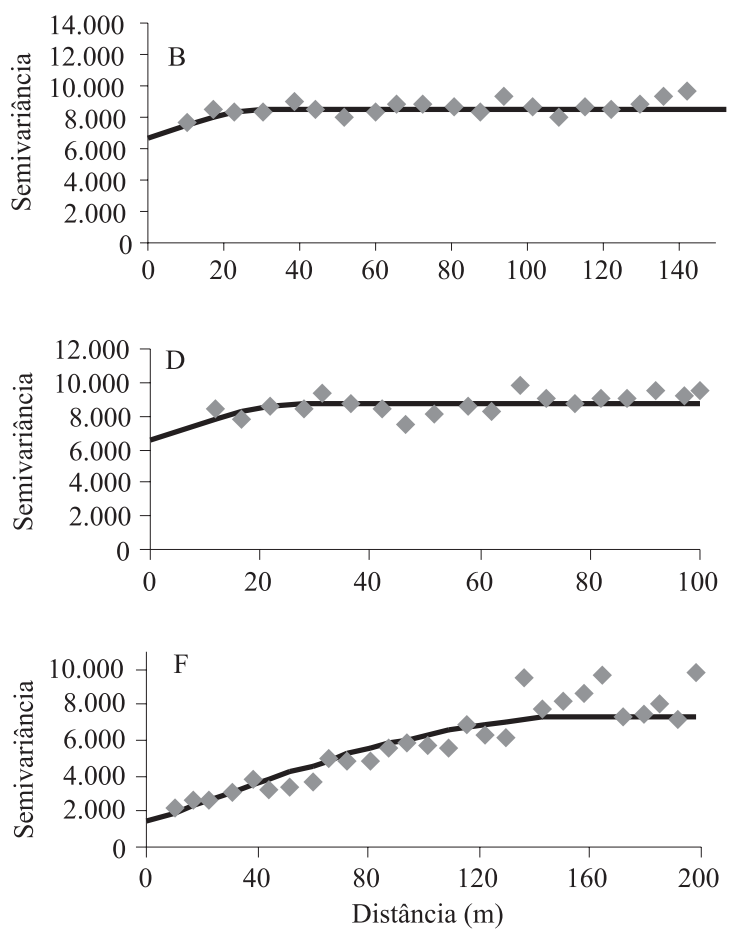

Figura 1. Semivariogramas da infiltração de água no solo, em agosto de 2004, nas profundidades de 0,10 (A) e 0,20 m (B); setembro de 2005, nas profundidades de 0,10 (C) e 0,20 m; e janeiro de 2006, nas profundidades de 0,10 (E) e $0,20 \mathrm{~m}$ (F). 
Os resultados encontrados neste trabalho reforçam o entendimento de que o manejo do pastejo, com destaque possivelmente para o controle da taxa de lotação animal e da oferta de forragem, pode ter influência sobre a sustentabilidade daatividadepecuária, quantoà conservação do solo e poluição e, também, em termos econômicos.
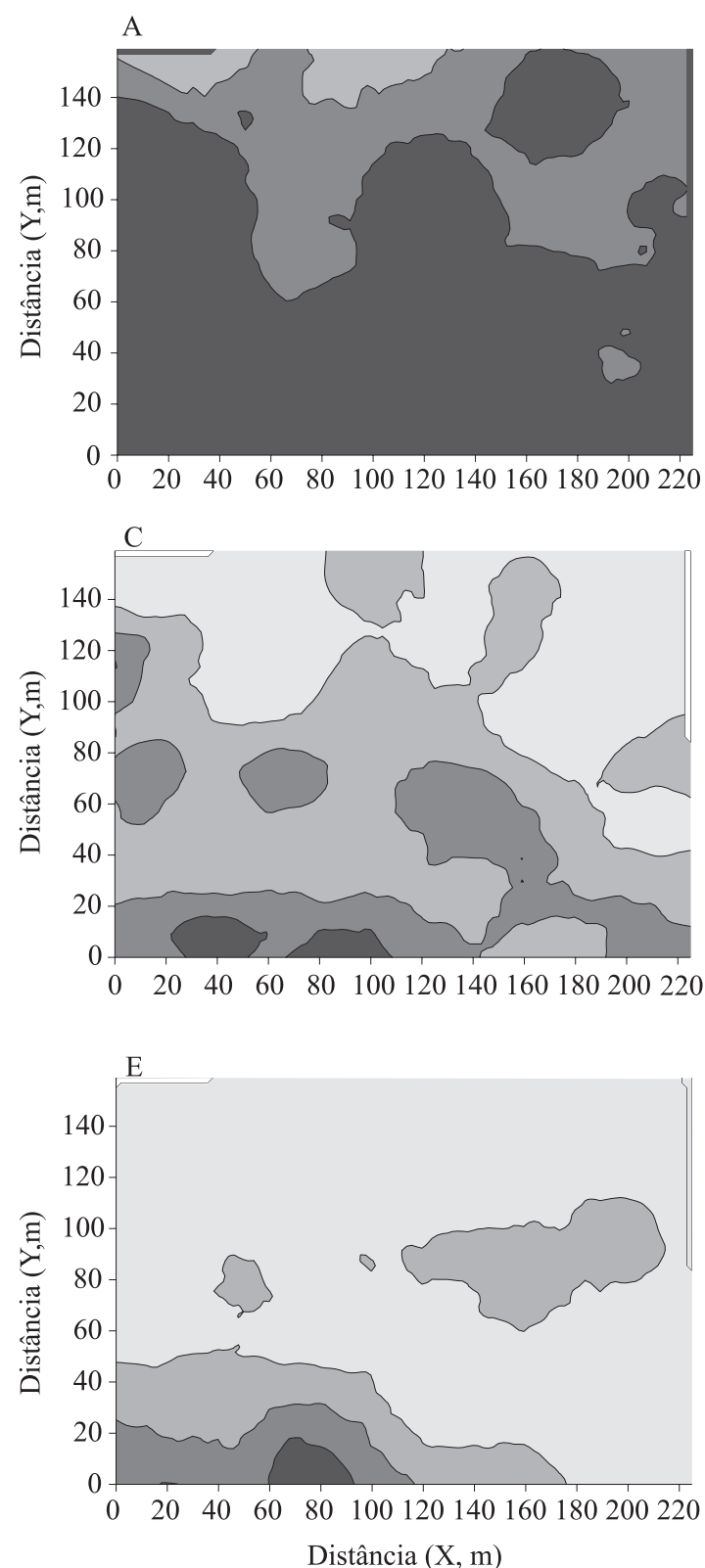

O estudo da variabilidade espacial da taxa de infiltração de água no solo, por meio da geoestatística, pode ser útil no manejo sustentável das pastagens, por possibilitar a construção de mapas que permitem a avaliação dos efeitos da intensificação do pisoteio do gado sobre as propriedades físicas do solo.
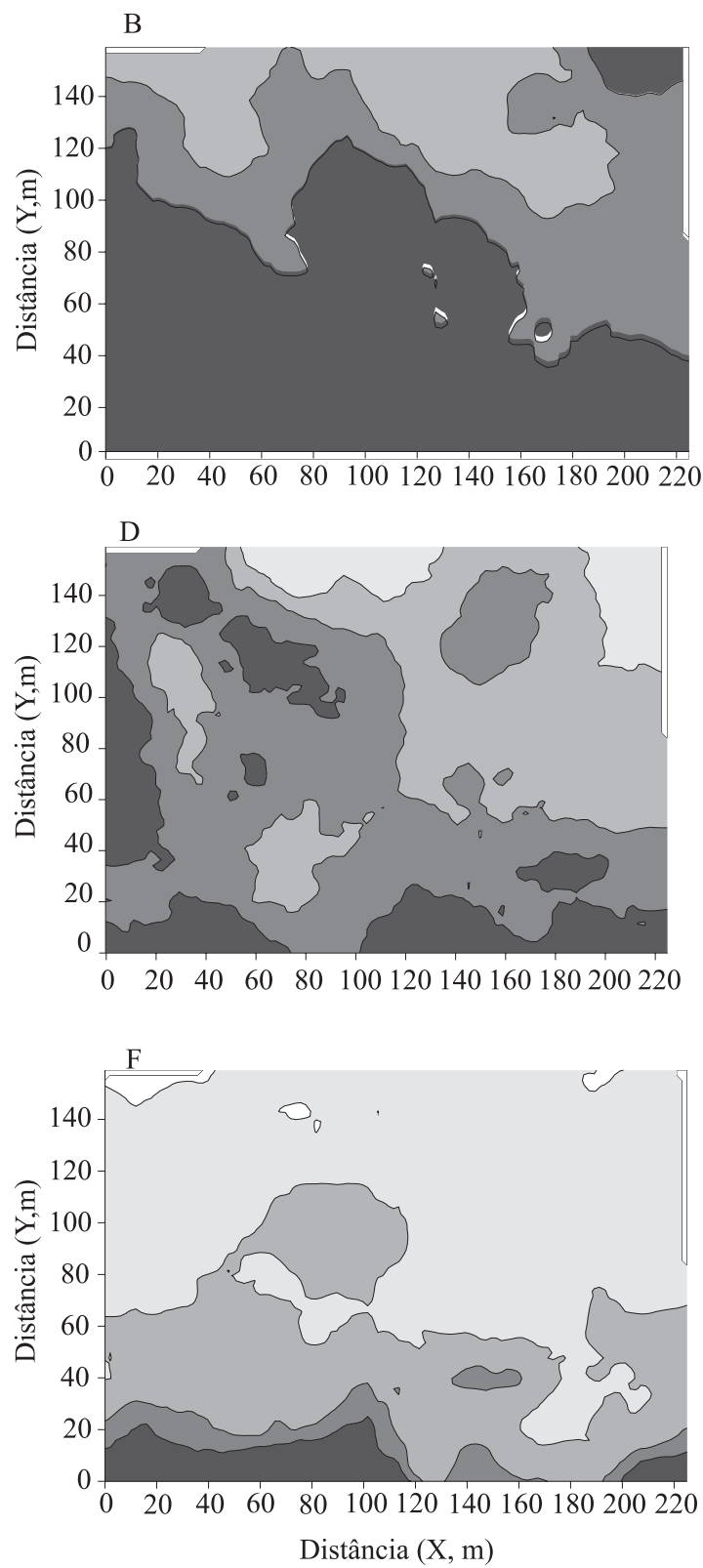

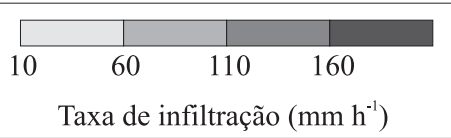

Figura 2. Mapas da taxa de infiltração de água no solo $\left(\mathrm{mm} \mathrm{h}^{-1}\right)$ em agosto de 2004 , nas profundidades de 0,10 (A) e $0,20 \mathrm{~m}(\mathrm{~B})$; setembro de 2005 , nas profundidades de 0,10 (C) e $0,20 \mathrm{~m}$ (D); e janeiro de 2006 , nas profundidades de $0,10(\mathrm{E})$ e $0,20 \mathrm{~m}(\mathrm{~F})$. 


\section{Conclusão}

A taxa de infiltração de água no solo apresenta estrutura de dependência espacial, que aumenta em função da intensidade de pisoteio.

\section{Referências}

ALVES, M.C.; CABEDA, M.S.V. Infiltração de água em um Podzólico Vermelho-Escuro sob dois métodos de preparo, usando chuva simulada com duas intensidades. Revista Brasileira de Ciência do Solo, v.23, p.753-761, 1999.

BERTOL, I.; ALMEIDA, J.A. de; ALMEIDA, E.X. de; KURTZ, C. Propriedades físicas do solo relacionadas a diferentes níveis de oferta de forragem capim-elefante-anão cv. Mott. Pesquisa Agropecuária Brasileira, v.35, p.1047-1054, 2000.

CALHEIROS, C.B.M.; TENÓRIO, F.J.C.; CUNHA, J.L.X.L.; SILVA, E.T. da; SILVA, D.F. da; SILVA, J.A.C. da. Definição da taxa de infiltração para dimensionamento de sistemas de irrigação por aspersão. Revista Brasileira de Engenharia Agrícola e Ambiental, v.13, p.665-670, 2009.

CICHOTA, R.; LIER, Q. de J. van; LEGUIZAMÓN ROJAS, C.A. Variabilidade espacial da taxa de infiltração em Argissolo Vermelho. Revista Brasileira de Ciência do Solo, v.27, p.789-798, 2003.

CRESSIE, N.A.C. Statistics for spatial data. New York: John Wiley \& Sons, 1991. 900p.

FIDALSKI, J.; TORMENA, C.A.; CECATO, U.; BARBERO, L.M.; LUGÃO, S.M.B; COSTA, M.A.T. Qualidade física do solo em pastagem adubada e sob pastejo contínuo. Pesquisa Agropecuária Brasileira, v.43, p.1583-1590, 2008.

FREEZE, R.A. A stochastic conceptual analysis of one-dimensional groundwater flow in nonuniform homogeneous media. Water Resources Research, v.11, p.725-742, 1975.

GOLDEN SOFTWARE. Surfer 7.0: contouring and 3D surface mapping for scientists and engineers: user's guide. New York: Golden Software, 1999. 619p.

GOMES, F.P. Curso de estatística experimental. Piracicaba: ESALQ/USP, 2000. 477p.

GREGO, C.R.; VIEIRA, S.R. Variabilidade espacial de propriedades físicas do solo em uma parcela experimental. Revista Brasileira de Ciência do Solo, v.29, p.169-177, 2005.

ISAAKS, E.H.; SRIVASTAVA, R.M. An introduction to applied geostatistics. New York: Oxford University, 1989. 561p.

KURZ, I.; O'REILLY, C.D.; TUNNEY, H. Impact of cattle on soil physical properties and nutrient concentrations in overland flow from pasture in Ireland. Agriculture, Ecosystems \& Environment, v.113, p.378-390, 2006.

LANZANOVA, M.E.; NICOLOSO, R. da S.; LOVATO, T.; ELTZ, F.L.F.; AMADO, T.J.C.; REINERT, D.J. Atributos físicos do solo em sistema de integração lavoura-pecuária sob plantio direto. Revista Brasileira de Ciência do Solo, v.31, p.1131-1140, 2007.
MONTENEGRO, A.A.A.; MONTENEGRO, S.M.G.L. Variabilidade espacial de classes de textura, salinidade e condutividade hidráulica de solos em planície aluvial. Revista Brasileira de Engenharia Agrícola e Ambiental, v. 10, p.30-37, 2006.

PREVEDELLO, C.L.; REICHARDT, K. Modelo tridimensional para medida da condutividade hidráulica de solos não saturados. Revista Brasileira de Ciência do Solo, v.15, p.121-124, 1991.

REICHERT, J.M.; REINERT, D.J.; BRAIDA, J.A. Qualidade dos solos e sustentabilidade de sistemas agrícolas. Revista Ciência \& Ambiente, v.27, p.29-48, 2003.

ROSOLEM, C.A.; VALE, L.S.R.; GRASSI FILHO, H.; MORAES, M.H. de. Sistema radicular e nutrição do milho em função da calagem e da compactação do solo. Revista Brasileira de Ciência do Solo, v.18, p.491-497, 1994.

SANTOS, H.G. dos; JACOMINE, P.K.T.; ANJOS, L.H.C. dos; OLIVEIRA, V.A. de; OLIVEIRA, J.B. de; COELHO, M.R.; LUMBRERAS, J.F.; CUNHA, T.J.F. (Ed.). Sistema brasileiro de classificação de solos. 2.ed. Rio de Janeiro: Embrapa Solos, 2006. 306p.

SARMENTO, P.; RODRIGUES, L.R. de A.; CRUZ, M.C.P. da; LUGÃO, S.M.B.; CAMPOS, F.P. de; CENTURION, J.F.; FERREIRA, M.E. Atributos químicos e físicos de um Argissolo cultivado com Panicum maximum Jacq. cv. IPR-86 Milênio, sob lotação rotacionada e adubado com nitrogênio. Revista Brasileira de Ciência do Solo, v.32, p.183-193, 2008.

SILVA, A.P. da; IMHOFF, S.; CORSI, M. Evaluation of soil compaction in an irrigated short-duration grazing system. Soil and Tillage Research, v.70, p.83-90, 2003.

SOUZA, G.S. de; LIMA, J.S. de S.; SILVA, S. de A.; OLIVEIRA, R.B. de. Variabilidade espacial de atributos químicos em um Argissolo sob pastagem. Acta Scientiarum. Agronomy, v.30, p.589-596, 2008.

VIEIRA, S.R. Geoestatística em estudos de variabilidade espacial do solo. In: NOVAIS, R.F. de; ALVAREZ V., V.H.; SCHAEFER, C.E.G.R. (Ed.). Tópicos em ciência do solo. Viçosa: Sociedade Brasileira de Ciência do solo, 2000. p.1-54.

VIEIRA, S.R. Permeâmetro: novo aliado na avaliação de manejo do solo. O Agronômico, v.47-50, p.32-33, 1998.

VIEIRA, S.R.; HATFIELD, J.L.; NIELSEN, D.R.; BIGGAR, J.W. Geoestatical theory and application to variability of some agronomical properties. Hilgardia, v.51, p.1-75, 1983.

VIEIRA, S.R.; LOMBARDI NETO, F. Variabilidade espacial do potencial de erosão das chuvas do Estado de São Paulo. Bragantia, v.54, p.405-412, 1995.

VIEIRA, S.R.; NIELSEN, D.R.; BIGGAR, J.W. Spatial variability of field-measured infiltration rate. Soil Science Society of America Journal, v.45, p.1040-1048, 1981.

ZIMBACK, C.R.L. Análise espacial de atributos químicos de solos para fins de mapeamento da fertilidade do solo. 2001. 114p. Dissertação (Livre Docência) - Universidade Estadual Paulista, Botucatu.

$\overline{\text { Recebido em } 16 \text { de abril de } 2009 \text { e aprovado em } 25 \text { de outubro de } 2009}$ 